\title{
Evolution of the thoracic surgeon educator: Incorporating education science into our DNA
}

Jules Lin, MD

Feature Editor Introduction-Challenges in cardiothoracic resident education have been a part of our specialty from the outset. The technical complexity, ever-increasing body of knowledge, and long work hours have challenged the best and brightest residents over the last several decades. Today, this has been amplified by a decrease in autonomy due to regulatory restrictions, increased scrutiny on outcomes, and increased work hour restrictions. This has resulted in decreased continuity of care and an overall decrease in the competency of graduating trainees. The rise of integrated training programs has attempted to mitigate these forces by allowing for increased exposure to the field and forcing faculty to reexamine their teaching paradigms to accommodate less-experienced trainees. Faculty at teaching institutions are also under siege, with an increased emphasis on clinical productivity and an ever-decreasing grant pay-line. Finally, the practice of cardiothoracic surgery has become more complex with the advent of minimally invasive and transcatheter techniques with ongoing growth in cardiothoracic knowledge over the last several decades.

Because of these challenges, competency-based training paradigms have flourished at some institutions. Innovations such as technical coaching, surgical simulation, and online-based feedback have been developed and are in practice. Although these have been important steps forward, testing the success of these novel methods is lacking and has been a barrier to universal adoption by all centers. We are encouraged by the increased presence of education research seen at national meetings and journals in our field; however, it is insufficient.

In this expert opinion piece on the evolution of cardiothoracic surgery training, the need for education research to refine our cardiothoracic training curriculum for the 21st century is well elucidated. We have come

\footnotetext{
From the Section of Thoracic Surgery, Department of Surgery, University of Michigan Medical Center, Ann Arbor, Mich.

Received for publication June 10, 2020; revisions received Oct 9, 2020; accepted for publication Oct 10, 2020; available ahead of print Nov 21, 2020.

Address for reprints: Jules Lin, MD, Section of Thoracic Surgery, 1500 E Medical Center Drive, 2120TC/5344, Ann Arbor, MI 48109-5344 (E-mail: juleslin@ umich.edu).

J Thorac Cardiovasc Surg 2021;162:503-9

$0022-5223 / \$ 36.00$

Copyright (C) 2020 by The American Association for Thoracic Surgery

https://doi.org/10.1016/j.jtcvs.2020.10.134
}

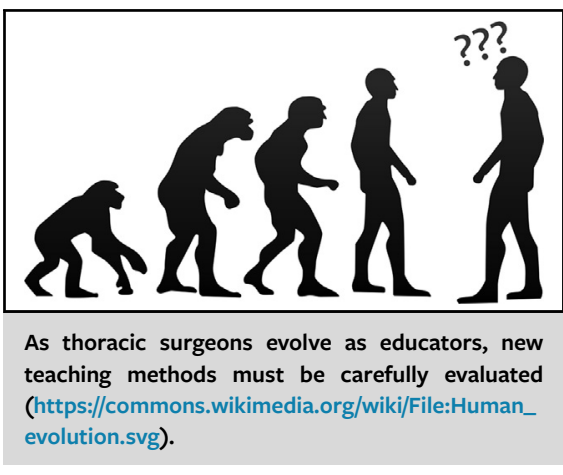

$$
\begin{aligned}
& \text { CENTRAL MESSAGE } \\
& \text { With competing demands for } \\
& \text { their time, surgeon educators } \\
& \text { continue to evolve by incorpo- } \\
& \text { rating new teaching methods but } \\
& \text { need to carefully evaluate these } \\
& \text { initiatives to determine their } \\
& \text { validity and value. }
\end{aligned}
$$

This Invited Expert Opinion provides a perspec tive on the following paper: J Am Coll Cardiol. 2019 Nov 5;74(18):2322-2325. 1016/j.jacc.2019.09.031. PMID: 31672189.

See Commentaries on pages 510 and 512.

from a rich history of investigation in clinical science; let us apply those principles to educating the next generation.

\section{Jason Zakko, MD, MS, and Nahush A. Mokadam, MD}

Since the time of the surgeon-barber, the apprenticeship model has been central to surgical education. At the beginning of the 20th century, Dr William Halsted established the Halsted model for surgical training with repetitive opportunities to care for surgical patients under the direction of a skilled surgeon and graduated responsibility with each advancing year. The Flexner Report in 1910 transformed medical schools in the United States establishing a model for medical education with higher standards resulting in the closure of almost half of medical schools. However, after World War II, research grew as a priority with expansion of the National Institutes of Health, and clinical productivity has become increasingly important since the establishment of 
Medicare and Medicaid in 1965 with less time for medical education. ${ }^{1}$ Although many surgeons have trained under the Halsted model, it is becoming increasingly clear that the current training system is inadequate. There has been a renewed interest in novel teaching methods, and in a recent article in the Journal of the American College of Cardiology, Cullen ${ }^{2}$ argues that educating cardiologists requires a distinct approach due to the integration of intellectual, clinical, and technical skills and that this presents a great opportunity for fellows and cardiologists to become involved in education science.

In a similar fashion, educating thoracic surgeons requires an integrated approach to teaching surgical knowledge, clinical management, and technical skills. Surgery is derived from the Greek word cheirourgos, or "working by hand," and hands-on learning remains an important part of surgical education. However, with the increasing complexity of patients, changing needs of our adult learners, and limited time available for the learner with work-hour restrictions and the educator with increasing regulatory and financial demands, surgeon educators must continue to evolve to be effective.

\section{EVOLUTION OF THE THORACIC SURGEON EDUCATOR \\ Evolutionary Pressure}

There have been substantial changes in cardiothoracic resident education over the last decade, and new teaching approaches are needed. Work-hour restrictions have decreased bedside hours, leading to less continuity. Connors and colleagues ${ }^{3}$ found a decrease in cardiac cases logged by cardiothoracic surgery residents after duty-hour restrictions. Another study evaluated the probability of meeting certification requirements for more rare, unscheduled cases such as cardiothoracic transplants. Although there was enough volume, due to work-hour restrictions only $55 \%$ of residents would meet the certification requirements. ${ }^{4}$ Although the 80-hour work week has limited the time available to teach individual residents, growth of integrated 6-year and 4/3 programs has led to earlier exposure requiring surgeons to adjust their teaching methods for less-experienced learners requiring more supervision and guidance. The growth in cardiothoracic knowledge during a 2-year fellowship has increased exponentially from 2000 publications in 1970 to 10,000 publications in $2015 .{ }^{5}$ More efficient methods of educating our residents are needed, and teaching the skills required for effective lifelong learning is essential. The traditional surgical apprenticeship model was effective but is labor intensive, and competing demands on faculty with an emphasis on research productivity, growing scrutiny of outcomes, and pressure to increase clinical revenue require new approaches including simulation, coaching, competency-based assessment, online courses, and systems that protect and reward teaching and mentorship.

\section{Competency-Based Assessment}

Evaluation of residents has shifted from one based mainly on time or case volume to competency-based assessment with a holistic evaluation of a trainee's progression to a competent surgeon with more frequent, real-time evaluation and feedback. Competency-based assessment is needed with the growth in volume of cardiothoracic surgical knowledge, complexity of cases, changing technology, and variable exposure to increasingly less common cases. Competency-based frameworks have been adopted internationally in surgical education including the Canadian Medical Education Directives for Specialists in 1996 and the Intercollegiate Surgical Curriculum in the United Kingdom in 2007.,

In 1999, the Accreditation Commission for Graduate Medical Education (ACGME) approved 6 core competencies for physician training, including patient care and procedural skills, medical knowledge, professionalism, systems-based practice, interpersonal and communication skills, and practice-based learning and improvement. To encourage application of these competencies to individual trainees and different specialties, the ACGME introduced Milestones in 2009 with individual disease or specialty-specific elements to assess a trainee's progression from a novice learner to a competent surgeon. In 2014, 25 thoracic surgery milestones developed by the American Board of Thoracic Surgery (ABTS) and ACGME were introduced. ${ }^{8}$ Individual programs were to determine how to assess and rate their residents, and the milestones were not meant to be used for promotion or graduation. The next version of the Thoracic Milestones 2.0 is currently being implemented with efforts to simplify the milestones, address new technologies such as robotic surgery, and provide additional assessment tools and resources. ${ }^{9}$

\section{Innovations in Education}

Coaching. Although coaching is used effectively in other disciplines, surgical coaching remains relatively uncommon. Traditional methods of teaching often include learning by observation, the classic "See one, do one, teach one" approach. Coaching encourages self-reflection using facilitated feedback individualized to each trainee's needs and goals and can benefit surgeons at all levels. Although coaching includes aspects of teaching and mentoring, coaching focuses on improving and refining existing skills and can be useful throughout one's surgical career. ${ }^{10}$ Coaching incorporates the idea of deliberate practice by actively identifying areas for improvement by reflecting on performance, making adjustments, and evaluating the impact of these changes. There is also increasing interest 
in using video recordings to assess technical skills and give feedback. Incorporating lessons learned through self-assessment and increased self-awareness may increase efficiency both inside and outside of the operating room.

Simulation. With fewer opportunities to see complicated, less common cases, the increasing amount of knowledge needed, advancements in technology, and increasing scrutiny of outcomes, simulation can provide residents with experience managing intraoperative disasters and practicing specific technical aspects of cannulation, anastomotic technique, and thoracoscopic or robotic surgery in a safe environment without putting patients at risk. Grants from the Western Thoracic Surgical Association and the European Association for Cardiothoracic Surgery (EACTS) have led to the development of several high- and low-fidelity cardiac and thoracic simulators. ${ }^{11,12}$ Although simulation can be an important component of surgical skills training, it is essential to integrate Anders Ericsson's ${ }^{13}$ concept of deliberate practice, including motivation, setting specific and realistic goals, pushing beyond one's comfort zone, being persistent, and seeking feedback.

In a prospective study evaluating 27 first-year cardiothoracic residents at 8 institutions, adoption of a comprehensive cardiac surgery simulation curriculum resulted in significant improvement in technical skills and decision-making in the management of adverse events during the training period. ${ }^{14,15}$ At the University of Michigan, boot camp courses have been developed to help medical students transition to residency by practicing chest tube insertion, central line placement, and tracheostomy in cadavers. ${ }^{16}$ Dr Mark Orringer is also developing a simulator for the cervical esophagogastric anastomosis component of an esophagectomy, guided by an illustrated curriculum, in collaboration with a product design engineer and faculty from the Department of Learning Health Sciences (Figure 1). A pilot study evaluating the content fidelity of the simulator (physical attributes, realism of materials, realism of experience, and value) suggests that the cervical esophagogastric anastomosis simulator is valuable as a surgical training tool (Figure 2). ${ }^{17}$

Residents have the opportunity to attend an annual resident boot camp organized by the Thoracic Surgical Directors Association using high-fidelity simulators for coronary anastomoses, aortic and mitral valve surgery, open and robotic lobectomy, and the management of cardiopulmonary bypass. Fann and colleagues ${ }^{12}$ reported that the ability to perform coronary anastomoses improved after using a porcine model, and Macfie and colleagues ${ }^{18}$ found improvement in all graded components after using a porcine lung model to practice hilar dissection. Chan and colleagues ${ }^{19}$ reported that residents had increased

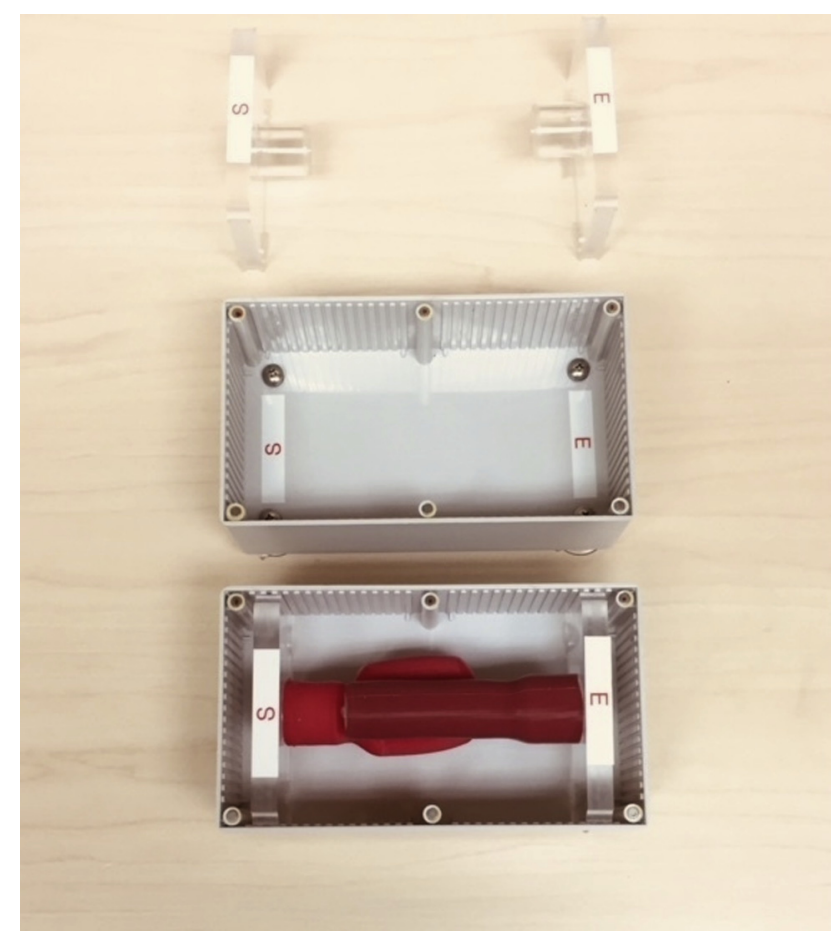

FIGURE 1. Cervical esophagogastric anastomotic simulator box with removable plastic supports (top) upon which silicone castings of both the gastric tip (S) and divided esophagus (E) are mounted and returned to the box base (bottom). (Reprinted with permission from Orringer and colleagues. ${ }^{17}$ )

confidence in transitioning to cardiothoracic residency after completing a simulation course. The ABTS has mandated that residents have at least 20 hours of simulation training during residency.

Online curriculum. With the rapidly expanding amount and complexity of cardiothoracic knowledge, a more efficient method of education is needed. Electronic learning materials can be easily accessed and continuously updated, provide formative self-assessment and feedback during the learning process, and allow the learner to work at his or her own pace. An online course with 4 modules focusing on tracheal surgery, an area that trainees have consistently performed poorly on the ABTS written board examination, was developed by the Joint Council on Thoracic Surgery Education in a pilot study of 19 residents from 4 institutions. The results demonstrated active learning, and residents perceived benefits from the content and quizzes. ${ }^{20}$

On the basis of these results, a national Thoracic Surgery Online Curriculum corresponding to the ABTS curriculum was developed including a learning management system with online articles, chapters, cases, and questions curated by an editorial board of cardiothoracic surgeons (learnctsurgery.sts.org) and available for residents and surgical faculty to use for didactic sessions and self-assessment. In a study of 187 trainees taking the 


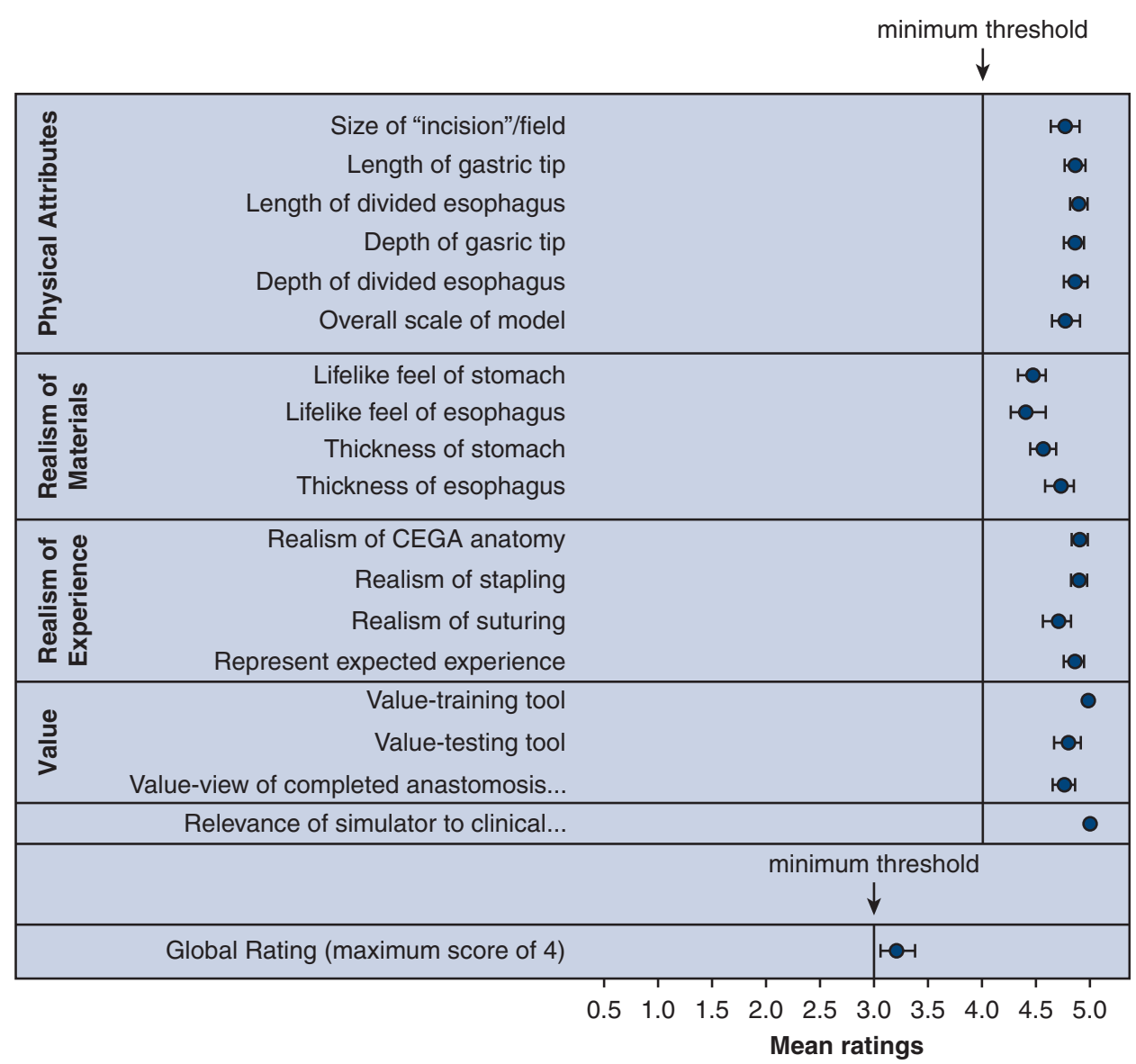

FIGURE 2. Participant $(\mathrm{n}=15)$ observed averages of the content fidelity of the cervical esophagogastric anastomotic $(C E G A)$ simulator measured using an evaluation form were all over the minimum cutoff of 4.00 or more. The Global item had a "minimum adequate threshold" of 3.0. (Reprinted with permission from Orringer and colleagues. ${ }^{17}$ )

in-training examination, scores of high-volume users trended toward greater improvement, and those with mid-range scores improved the most. $^{21}$ Luc and

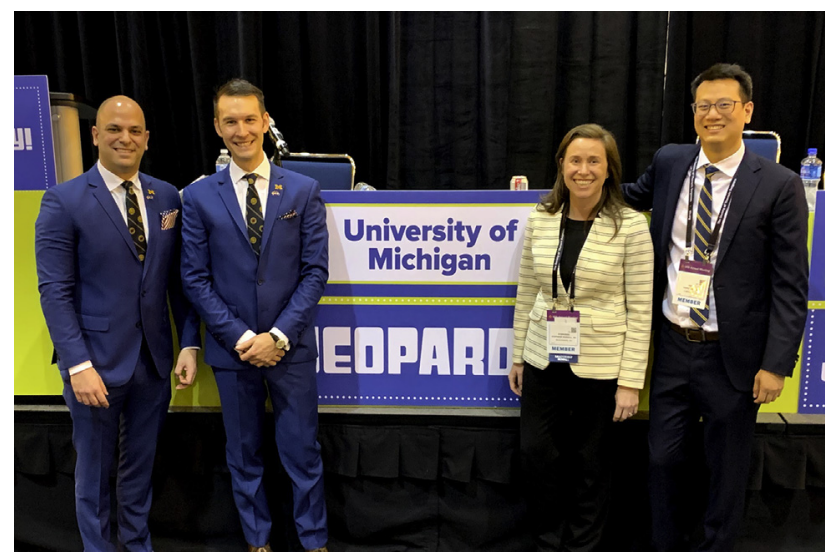

FIGURE 3. Gamification of thoracic surgical education. The 2020 (Alex Brescia and Curtis Bergquist) and 2018 (Stephanie Worrell and Terry Shih) Jeopardy champions from University of Michigan. colleagues $^{22}$ evaluated log-in frequency in the final month before the in-service examination and found that those who improved their scores the most year to year accessed the curriculum more often in the last month. Developing the online curriculum has required curation of an enormous amount of content with the increasing number of publications, overlapping content from different sources, and fees to use content. In addition, traditional book chapters are often out of date by the time of publication. To address these issues, electronic textbooks for thoracic, cardiac, and congenital cardiac surgery are being developed by the Society of Thoracic Surgeons (STS) for release in 2020 and have the advantage of being continuously updated and tailored to match the online curriculum.

Gamification. Novel teaching methods including the use of competition to fuel performance can be used to increase excitement about learning and encourage the use of simulators due to the competitive nature of surgical residents. In the Top Gun competition held at the STS annual meeting, 5 resident finalists competed using low-fidelity coronary anastomotic simulators with evidence 
of improvement in all areas of assessment. ${ }^{23}$ The joint EACTS/STS Jeopardy competition is also held at the STS annual meeting testing the best North American team against the best European team in their knowledge of cardiothoracic surgery (Figure 3). Finalists reported increased use of the Thoracic Surgery Online Curriculum by an average of 10 hours per week.

Mobile applications. At the University of Michigan, a novel Minute Feedback System has been implemented, allowing faculty to provide timely feedback to students using a web-based form immediately after an operative case $^{24}$ Application-based feedback using Zwisch Me provides immediate written feedback to residents on their operative performance, which was most useful in addressing surgical technique and error prevention. ${ }^{25}$ In addition, high-frequency resident users of the System for Improving and Measuring Procedural Learning (SIMPL) application for evaluating operative autonomy and providing feedback were more likely to perceive a benefit. ${ }^{26}$

\section{INCORPORATING EDUCATION SCIENCE INTO OUR DNA}

As thoracic surgeons continue to evolve as educators and implement novel teaching methods, we must incorporate education science into our skill set so we not only rigorously evaluate the validity of these educational tools but also add our experience to the growing literature on thoracic surgical education disseminating ideas to other programs. Antonoff and colleagues ${ }^{27}$ review key concepts in conducting high-quality research in cardiothoracic surgical education
(Figure 4) including hypothesis-driven research, appropriate study design, adequate power and sample size, and collaboration with others skilled in educational research. There is a need to improve the quality of publications on cardiothoracic surgical education with less than $5 \%$ of articles with an experimental basis and $56 \%$ without an appropriate control group. ${ }^{27}$ Tools have also been developed to evaluate the quality of publications on medical education including the Medical Education Research Study Quality Instrument and the Newcastle-Ottawa Scale-Education. ${ }^{28}$

\section{Opportunities}

Although there have been concerns in the past about whether education science is as prestigious as basic or clinical science, educational research has grown rapidly over the past decade with sessions at national meetings and sections in thoracic journals dedicated to education. Educational grants are also available from the Thoracic Surgery Foundation, EACTS, and Western Thoracic Surgical Association, and the quality of education research is directly related to the degree of funding support. ${ }^{29}$ There are now opportunities to devote one's academic career to thoracic surgical education. New models need to be developed to recognize and reward teaching and to stimulate scholarly activity in education in the current challenging environment. Some institutions have implemented educator tracks and education portfolios for faculty promotion and teaching relative value units to reward educational efforts. ${ }^{30}$

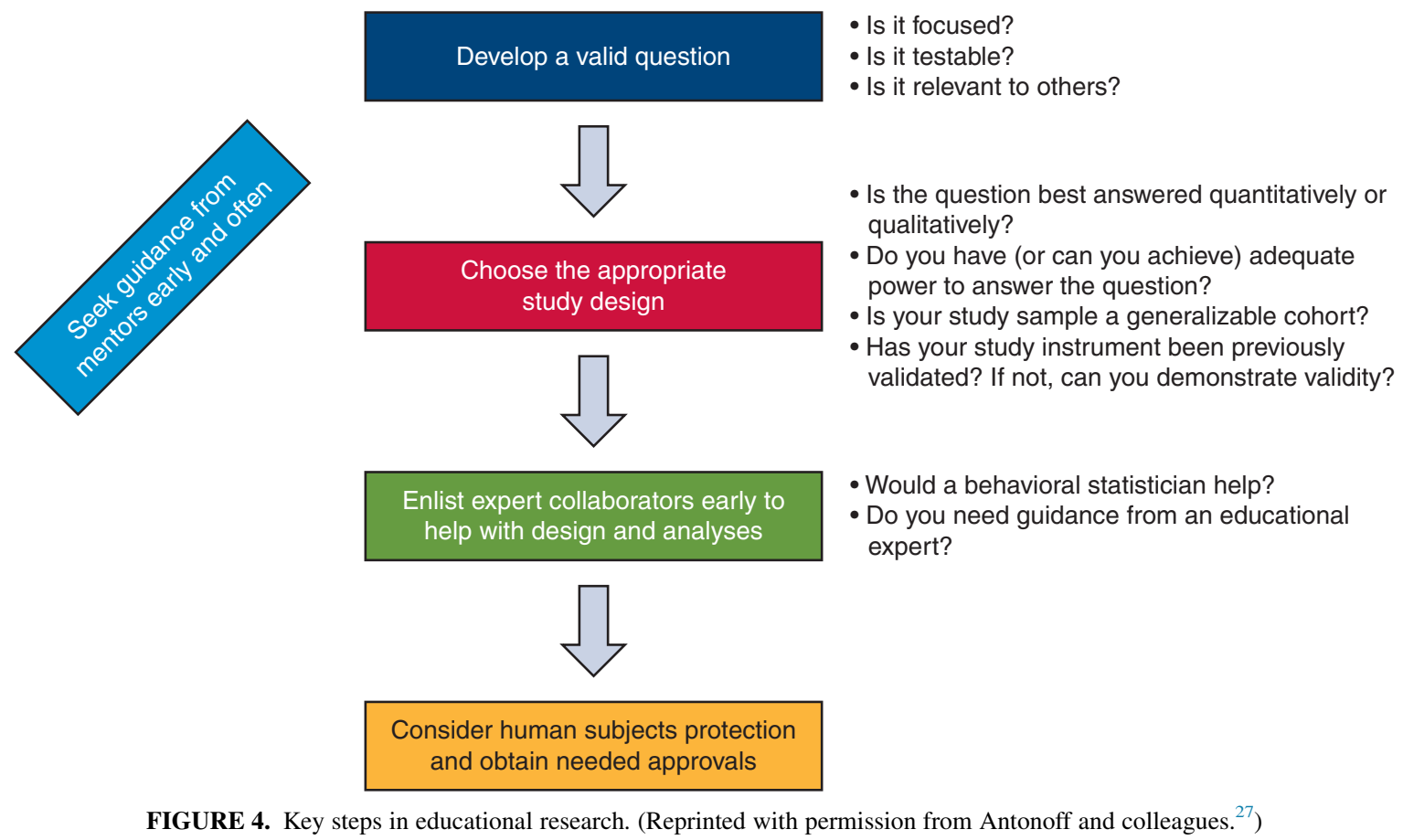

The Journal of Thoracic and Cardiovascular Surgery • Volume 162, Number 2 
One of the challenges in thoracic surgical education research is the relatively small number of trainees compared with large general surgery or medical residencies. The establishment of the Thoracic Education Collaborative Group encourages collaboration on multi-institutional studies with a larger number of study subjects, increasing the quality of these studies. ${ }^{31,32}$ The development of the STS Thoracic Surgery Online Curriculum provides an opportunity for surgical educators to gather objective, granular data on the frequency of use, modules reviewed, and time spent on the learning activity to evaluate the effect on clinical and testing performance. ${ }^{20-22}$

\section{Deliberate Approach to Developing Surgeon Educators}

As a specialty, we must take deliberate action to develop faculty into effective educators because technical expertise as a surgeon does not necessarily equal excellence as an educator. There has been increasing focus on developing more effective teachers through an Educate the Educator course sponsored by the Thoracic Surgical Directors Association providing training in fundamental teaching skills and curriculum development, and using education research for academic advancement. ${ }^{33}$

Training and empowering our residents to become surgical educators is critical to building momentum and creating a lasting culture of change. There has been increasing recognition of adult learning theory and that adults learn better by being actively involved in their learning. Knowles ${ }^{34}$ suggested 4 principles that apply to adult learning: (1) Learners need to be involved in planning for their instruction, (2) experience provides the basis for learning activities, (3) adults are most interested in subjects that are immediately relevant to their job, and (4) adult learning is problem-centered. ${ }^{34}$ Efforts to enable adult learners to be active participants in their learning include flipping the classroom by having residents teach interactive sessions using a case-based format with a faculty moderator as opposed to a traditional lecture format. Mokadam and colleagues $^{35}$ found that flipping the classroom stimulated resident participation and that residents who completed both curricular readings $(82 \%)$ and reviewed case presentations $(79 \%)$ performing significantly better on quizzes.

\section{CONCLUSIONS}

With competing demands for faculty time, growing scrutiny of clinical outcomes, pressure to increase clinical revenue, increasing complexity of patients, and substantial changes in cardiothoracic resident education, surgeon educators must continue to evolve by incorporating simulation, coaching, online resources, the skills necessary for lifelong learning, and systems that reward teaching and mentorship. As thoracic surgeons evolve as educators and implement novel teaching methods, we must rigorously evaluate the validity of these educational tools and disseminate these ideas by adding our experience to the growing literature on education in thoracic surgery, incorporating education science into our DNA.

\section{Conflict of Interest Statement}

J.L. is a surgical site mentor and robotic proctor for Intuitive Surgical.

The Journal policy requires editors and reviewers to disclose conflicts of interest and to decline handling or reviewing manuscripts for which they may have a conflict of interest. The editors and reviewers of this article have no conflicts of interest.

\section{References}

1. Ludmerer KM. Time to Heal: American Medical Education from the Turn of the Century to the Era of Managed Care. Oxford: Oxford University Press; 1999.

2. Cullen MW. Cardiovascular education science: a worthy pursuit for fellows-in-training and early career cardiologists? J Am Coll Cardiol. 2019;74: 2322-5.

3. Connors RC, Doty JR, Bull DA, May HT, Fullerton DA, Robbins RC. Effect of work-hour restriction on operative experience in cardiothoracic surgical residency training. J Thorac Cardiovasc Surg. 2009;137:710-3.

4. Chung J, Obi A, Chen R, Lin W, Sun S, Chen Z, et al. Estimating minimum program volume needed to train surgeons: when $4 \times 15$ really equals 90 . $J$ Surg Educ. 2015;72:61-7.

5. Vaporciyan AA. How to give effective formative feedback in thoracic surgery education. Thorac Surg Clin. 2019;29:249-57.

6. Phillips AW, Madhavan A. A critical evaluation of the Intercollegiate Surgical Curriculum and comparison with its predecessor the "Calman" curriculum. J Surg Educ. 2013;70:557-62.

7. Snell L, Frank JR, Sherbino J. The CanMEDS 2015 Physician Competency Framework. Ottawa: Royal College of Physicians and Surgeons of Canada; 2015.

8. Yang SC, Merrill W. Educational milestone development in phase II specialties: thoracic surgery. J Grad Med Educ. 2014;6:329-31.

9. Mitzman B, Beller JP, Edgar L. Thoracic surgery milestones 2.0: rationale and revision. J Thorac Cardiovasc Surg. 2020;160:1399-404.

10. Lin J, Reddy RM. Teaching, mentorship, and coaching in surgical education. Thorac Surg Clin. 2019;29:311-20.

11. De Raet JM, Arroyo J, Büchner S, Siregard S, Andreas M, Halvorsen F, et al. How to build your own coronary anastomosis simulator from scratch. Interact Cardiovasc Thorac Surg. 2013;16:772-6.

12. Fann JI, Calhoon JH, Carpenter AJ, Merrill WH, Brown JW, Poston RS, et al. Simulation in coronary artery anastomosis early in cardiothoracic surgical residency training: the Boot Camp experience. J Thorac Cardiovasc Surg. 2010;139:1275-81.

13. Ericsson KA. Acquisition and maintenance of medical expertise: a perspective from the expert-performance approach with deliberate practice. Acad Med. 2015;90:1471-86.

14. Feins RH, Burkhart HM, Conte JV, Coore DN, Fann JI, Hicks GL Jr, et al. Simulation-based training in cardiac surgery. Ann Thorac Surg. 2017;103: 312-21.

15. Mokadam NA, Fann JI, Hicks GL, Nesbitt JC, Burkhart HM, Conte JV, et al. Experience with the cardiac surgery simulation curriculum: results of the resident and faculty survey. Ann Thorac Surg. 2017;103:322-8.

16. Tocco N, Brunsvold M, Kabbani L, Lin J, Stansfield B, Mueller D, et al. Innovation in internship preparation: an operative anatomy course increases senior medical students' knowledge and confidence. Am J Surg. 2013;206: 269-79.

17. Orringer MB, Hennigar D, Lin J, Rooney DM. A novel cervical esophagogastric anastomosis simulator. J Thorac Cardiovasc Surg. 2020;160:1598-607.

18. Macfie RC, Webel AD, Nesbitt JC, Fann JI, Hicks GL, Feins RH. "Boot camp" simulator training in open hilar dissection in early cardiothoracic surgical residency. Ann Thorac Surg. 2014;97:161-6. 
19. Chan PG, Schaheen LW, Chan EG, Cook CC, Luketich JD, D'Cunha J. Technology-enhanced simulation improves trainee readiness transitioning to cardiothoracic training. J Surg Educ. 2018;75:1395-402.

20. Antonoff MB, Verrier ED, Yang SC, Lin J, DeArmond DT, Allen MS, et al. Online learning in thoracic surgical training: promising results of multi-institutional pilot study. Ann Thorac Surg. 2014;98:1057-63.

21. Antonoff MB, Verrier ED, Allen MS, Aloia L, Baker C, Fann JI, et al. Impact of Moodle-based online curriculum on thoracic surgery in-training examination scores. Ann Thorac Surg. 2016;102:1381-6.

22. Luc JGY, Verrier ED, Allen MS, Aloia L, Baker C, Fann JI, et al. Does cramming work? Impact of national web-based thoracic surgery curriculum login frequency on thoracic surgery in-training exam performance. J Thorac Cardiovasc Surg. 2018;156:922-7.

23. Mokadam NA, Lee R, Vaporciyan AA, Walker JD, Cerfolio RJ, Hermsen JL, et al. Gamification in thoracic surgical education: using competition to fuel performance. J Thorac Cardiovasc Surg. 2015;150:1052-8.

24. Hughes DT, Leininger L, Reddy RM, Sandhu G, Ryszawa S, Englesbe M. A novel minute feedback system for medical students. Am J Surg. 2017;213: 330-5.

25. Karim AS, Sternbach JM, Bender EM, Zwischenberger JB, Meyerson SL. Quality of operative performance feedback given to thoracic surgery residents using an app-based system. J Surg Educ. 2017;74:e81-7.

26. Eaton M, Scully R, Schuller M, Yang A, Smink D, Williams RG, et al. Value and barriers to use of the SIMPL tool for resident feedback. J Surg Educ. 2019;76: 620-7.

27. Antonoff MB, Nguyen S, Nguyen TC, Odell DD. Conducting high-quality research in cardiothoracic surgical education: recommendations from the Thoracic Education Cooperative Group. J Thorac Cardiovasc Surg. 2019;157: 820-7.e1.
28. Cook DA, Reed DA. Appraising the quality of medical education research methods: the medical education research study quality instrument and the Newcastle-Ottawa scale-education. Acad Med. 2015;90:1067-76.

29. Reed DA, Cook DA, Beckman TJ, Levine RB, Kern DE, Wright SM. Association between funding and quality of published medical education research. JAMA. 2007;298:1002-9.

30. Ma OJ, Hedges JR, Newgard CD. The academic RVU: ten years developing a metric for and financially incenting academic productivity at Oregon Health \& Science University. Acad Med. 2017;92:1138-44.

31. Loor G, Doud A, Nguyen TC, Antonoff MB, Morancy JD, Robich MP, et al Development and evaluation of a three-dimensional multistation cardiovascula simulator. Ann Thorac Surg. 2016;102:62-8.

32. Spratt JR, Brunsvold M, Joyce D, Nguyen T, Antonoff M, Loor G. Prospective trial of low-fidelity deliberate practice of aortic and coronary anastomoses (TECoG 002). J Surg Educ. 2019;76:844-55.

33. Yang SC, Vaporciyan AA, Mark RJ, DaRosa DA, Stritter FT, Sullivan ME, et al The Joint Council on Thoracic Surgery Education (JCTSE) "educate the educators" faculty development course: analysis of the first 5 years. Ann Thorac Surg. 2016;102:2127-32.

34. Knowles M. The Adult Learner: A Neglected Species. 3rd ed. Houston, TX: Gulf Publishing; 1984.

35. Mokadam NA, Dardas TF, Hermsen JL, Pal JD, Mulligan MS, Jacobs LM, et al Flipping the classroom: case-based learning, accountability, assessment, and feedback leads to a favorable change in culture. J Thorac Cardiovasc Surg. 2017;153:987-96.e981.

Key Words: surgical education, thoracic surgery, simulation, online curriculum 